\title{
Effect of the Perception of Knee Pain on Muscle Strength and Endurance among Elite Female Handball Players
}

\section{Auswirkung der Wahrnehmung von Knieschmerzen auf Muskelkraft und Ausdauer bei Elite-Handballerinnen}

Authors

ChanWoo Kim¹, Ki Jun Park²

\section{Affiliations \\ 1 Department of Health Science, Kangwon National University, Chuncheon, Korea (the Republic of) \\ 2 Department of Physical Therapy, Sang Ji University, Wonju, Korea (the Republic of)}

Keywords

Handball players, knee pain, muscle strength, muscle endurance

\section{Schlüsselwörter}

Handballspieler, Knieschmerzen, Muskelkraft, Ausdauer

received 20.09.2020

accepted 08.03 .2021

published online 16.04 .2021

Bibliography

Phys Med Rehab Kuror 2021; 31: 262-267

DOI 10.1055/a-1416-3937

ISSN 0940-6689

(c) 2021. Thieme. All rights reserved.

Georg Thieme Verlag KG, Rüdigerstraße 14,

70469 Stuttgart, Germany

Correspondence

Ki Jun Park

Department of Physical Therapy

Sang Ji University

83, Sangjidae-gil, Wonju-si

Gangwon-do, Republic of Korea

26339 Wonju

Korea (the Republic of)

koc-pt@sangji.ac.kr

\section{ABSTRACT}

Objectives This study aimed to examine the effect of knee pain perception on muscle strength and endurance among elite female handball players.

Methods This study included 60 handball players who participated in training and competition from January to December
2019. Muscle strength, endurance, and hamstring/quadriceps ratio of the knee were estimated using Computer Sports Medicine, INC (Cybex, HUMAC, USA). The independent samples t-test was used for inter-group comparison. The Pearson's correlation and simple linear regression analyses were used to assess associations among the variables and identify factors affecting pain perception, respectively.

Results No significant differences in knee muscle strength, endurance of both the flexor and extensor muscles, and muscle strength (hamstring/quadriceps ratio) were noted between the high and low groups. However, the ratio of muscle endurance of the flexor and extensor of the knee in the high group was significantly lower than that in the low group. Furthermore, pain was found to correlate only with muscle endurance (hamstring/quadriceps ratio). The pain scale reading increased by 1 . Moreover, muscle endurance ratio of the flexor and extensor muscles of the knee decreased by 3.07.

Conclusion Muscle endurance (hamstring/quadriceps ratio) of the flexor and extensor muscles, classified based on an average pain scale, differed between the high and low groups. These results can aid in development of rehabilitation and exercise programs for players involved in handball and similar sports in the future.

\section{ZUSAMMENFASSUNG}

Ziele Mit dieser Studie sollte die Auswirkung der Wahrnehmung von Knieschmerzen auf Muskelkraft und Ausdauer bei Elite-Handballerinnen untersucht werden.

Methoden Die Studie wurde von Januar bis Dezember 2019 mit 60 Handballspielerinnen durchgeführt, die in diesem Zeitraum an Training und Wettkämpfen teilnahmen. Muskelkraft, Ausdauer und das Hamstrings/Quadriceps-Verhältnis des Knies wurden mithilfe von Computer Sports Medicine, INC (Cybex, HUMAC, USA) bewertet. Für den Vergleich zwischen den Gruppen wurde der t-Test für unabhängige Stichproben verwendet. Die Pearson-Korrelation und einfache lineare Regressionsanalysen wurden verwendet, um Assoziationen zwischen den Variablen zu bewerten bzw. Faktoren zu identifizieren, die das Schmerzempfinden beeinflussen.

Ergebnisse Es konnten keine signifikanten Unterschiede in der muskulären Kraftfähigkeit des Kniegelenks, der Ausdauer der 
Beuger- und Streckermuskeln und der Muskelkraft (Verhältnis Hamstring/Quadrizeps) zwischen der hohen und der niedrigen Gruppen festgestellt werden. Allerdings war das Verhältnis der Ausdauer der Beuger- und Streckermuskulatur des Knies in der hohen Gruppe signifikant geringer als in der niedrigen Gruppe. Zudem korrelierte die Schmerzintensität nur mit der Muskelausdauer (Verhältnis Hamstring/Quadriceps). Der Wert auf der Schmerzskala stieg um 1. Außerdem sank das Verhältnis der
Muskelausdauer der Beuge- und Streckmuskeln des Knies um 3,07 .

Schlussfolgerung Die Ausdauer (Hamstring/Quadrizeps-Verhältnis) der Beuge- und Streckmuskeln, die basierend auf einer gängigen Schmerzskala eingeschätzt wurde, unterschied sich zwischen der hohen und der niedrigen Gruppe. Diese Ergebnisse können bei der Entwicklung von Rehabilitations- und Trainingsprogrammen für Sportler im Handball oder ähnlichen Sportarten in Zukunft hilfreich sein.

\section{Introduction}

Handball is a team sport and one of the official Olympic events in which approximately 1.13 million teams from 180 countries worldwide participate [1]. The Korean women's handball team currently has eight functional teams comprising 110 players [2]. Despite economic hardship, the nation, as a powerhouse in handball, improvises high-level training and team play to maintain the top position not only in Asia but also throughout the globe [3]. However, handball is associated with an extremely high injury incidence across all sports due to its rules and nature of the game necessitating intense physical contact with opponents, frequent running, and fast turning and cheating [4].

Sports injuries are sustained due to sports-related activities, such as training and different types of games. Consequently, players have to take breaks from sporting events for diagnosis and treatment [5]. In particular, sports injuries are crucial issues that cannot be overlooked by players because these injuries could adversely affect their performance and may also prematurely terminate their careers $[6,7]$. Although sports medicine is a fast-growing field, most research in sports medicine revolves around epidemiological studies and treatment and rehabilitation from sports injuries [8-10]. However, to date, studies on prevention of sports injuries are sparse.

According to Kim and Park [8], Korean elite female handball players sustain a high incidence of sports injuries to their knees due to operational patterns involved in the game, such as: swift attacks, quick turns, attacks using wing positions, and unstable landing after jumping. Knee injury and pain lead to reduced motor function and muscle strength [11], thereby necessitating the performance of exercises as rehabilitative measures [11]. Bala et al. [12] emphasized the necessity for strengthening endurance of players because injury leads to reduced muscle endurance. However, to the best of our knowledge, no study has evaluated the direct effect of muscle strength on pain perception, and more research is needed to fill a gap in this field. Therefore, this study was conducted among elite female handball players having knee injuries to evaluate the correlation between knee pain perception and knee muscle strength and muscle endurance. Similarly, we aimed to identify factors affecting perception of knee pain to develop rehabilitation and athletic programs among handball players to improve their performance in the future.

\section{Methods}

\section{Study population}

The study was conducted among elite female handball players aged $\geq 18$ years who participated in high-level competitions and were trained at a training center from January 2019 to December 2019. Players who had serious injuries that prevented them from participating in competitions and training were excluded from the study. The study was conducted in accordance with the Declaration of Helsinki after obtaining an approval from the Institutional Review Board. All study participants provided informed consent. In total, 60 players with knee pain participated in the study after consulting sports medicine specialists ( $\triangleright$ Table $\mathbf{1}$ ).

\section{Data collection}

A pain scale (Numerical rating scale; NRS) was used to rate pain perception from 0 (least) to 10 (highest) [13]. In addition, to compare muscle strength and endurance of the knees, peak torque and total work hamstring/quadriceps $(\mathrm{H} / \mathrm{Q})$ ratio of the knee were measured by the continental/concentric method using Computer Sports Medicine, INC (Cybex, HUMAC, USA). Elite female handball players were encouraged by their physical therapists to use their strengths to the fullest extent through pre-training at the time of assessment.

\section{Operational definitions}

Muscle strength and endurance were assessed, as previously described in a study of dynamic muscle strength evaluation in elite players [14]. Muscle strength was measured five times at a load speed of $60 \%$. Muscle endurance was measured 20 times at a load speed of $180 \%$. The operating range of the knee was set from $0{ }^{\circ}$ to $90^{\circ}$. The target activity was prevented by fixing the body and the pelvis in an X-shaped manner, with straps attached to the measuring equipment over both shoulders. In addition, muscle strength was measured at first, followed by a five-minute rest in the most comfortable position to recover from inorganic phosphoric acid (Pi) and force produced by muscle contraction [14]. The H/Q ratio of the flexor and extensor muscles of the knee was calculated as flexor muscles/extensor $\times 100$.

\section{Statistical analyses}

The general characteristics of the players were analyzed using descriptive statistics. An independent sample $t$-test was performed to compare the ratio of the flexor and extensor muscles $(\mathrm{H} / \mathrm{Q})$ of 
the knee and muscle strength of the knee between the high and low groups. In addition, the Pearson's correlation and simple linear regression analyses were used to assess associations among the variables and identify the factors affecting pain. All statistical analyses were performed using SPSS version 26.0 for Windows, and all statistical significance levels were set at $\alpha=0.05$.

\section{Results}

The overall mean knee pain scale of elite female handball players was 4.57 (5.47 and 3.67 in the high and low groups, respectively). The knee flexor and extensor muscle (H/Q) ratio was 120.58 \pm 17.31 $\mathrm{NM}$ in the high group and $120.00 \pm 11.06 \mathrm{NM}$ in the low group. The knee extensor muscle strength was $222.83 \pm 24.63 \mathrm{NM}$ in the high group and $215.31 \pm 23.17 \mathrm{NM}$ in the low group, and the results of both the flexor and extensor muscles were similar between the 2 groups ( $\triangleright$ Table 2 ). Muscle endurance of the knee flexor muscle was $86.08 \pm 10.92 \mathrm{NM}$ in the high group and 90.44 $\pm 10.02 \mathrm{NM}$ in the low group. The endurance of the knee extensor muscle was $147.25 \pm 12.74 \mathrm{NM}$ in the high group and $140.86 \pm 17.98 \mathrm{NM}$ in the low group, and the results of both the flexor and extensor muscles were similar between the 2 groups ( $>$ Table 2 ). Muscle strength

- Table 1 General characteristics of the participants.

\begin{tabular}{|l|r|r|}
\hline & Mean & SD \\
\hline Age (years) & 28.54 & 3.46 \\
\hline Player career (years) & 16.71 & 3.44 \\
\hline Height $(\mathrm{cm})$ & 167.7 & 4.71 \\
\hline Weight $(\mathrm{kg})$ & 60.2 & 5.02 \\
\hline SD: standard deviation. & & \\
\hline
\end{tabular}

ratio of the knee flexor and extensor muscle (H/Q ratio) was similar between the 2 groups ( $54.57 \pm 8.81$ and $56.22 \pm 7.14 \mathrm{NM}$ in the high and low groups, respectively) ( $\triangleright$ Table 2 ). However, the ratio of muscle endurance of the flexor and extensor of the knee in the high group was significantly lower than that in the low group $(58.56 \pm 6.70$ vs. $64.66 \pm 6.58 \mathrm{NM} ; p=0.001)$ ( $>$ Table 2$)$. The pain perception (pain scale) correlated only with the muscle endurance ratio of the knee flexor and extensor muscles ( $>$ Table 3 ). The pain scale reading increased by 1 . The muscle endurance ratio of the flexor and extensor muscles of the knee decreased by 3.07 ( $\triangleright$ Table 4).

\section{Discussion}

Sports injury is an important issue that needs to be considered for improving performance and maintaining regular sports activity [6]. Handball players have a high incidence of sports injury to their knees [14]. Therefore, it is important to identify factors directly affecting perception of knee pain. We aimed to identify factors affecting this perception of knee pain among handball players and generate data necessary to develop rehabilitation programs to improve performance in these players in the future.

In this study, no significant differences in knee muscle strength, endurance of both the flexor and extensor muscles, and muscle strength (H/Q ratio) were noted between the high and low groups. However, the ratio of muscle endurance of the flexor and extensor of the knee in the high group was significantly lower than that in the low group. The perception of pain did not correlate with muscle strength of the flexor and extensor muscles of the knee. In general, knee injury and diminished motor function led to pain and muscle weakness [11], which further resulted in reduced muscle endurance [12]. However, it is unclear whether assessment of muscle strength and endurance could accurately predict the risk of knee injury and pain, as well as degradation of motor functions [15].Of note, there are some differences between the results of this study and those of previous ones $[11,12]$. The possibility that muscle

- Table 2 Differences in muscle power and muscle endurance between the 2 groups.

\begin{tabular}{|c|c|c|c|c|c|}
\hline & & Mean & SD & $\mathbf{F}$ & p-value \\
\hline \multirow[t]{2}{*}{ Flexor of $60 \%$} & High group & 120.58 & 17.32 & \multirow[t]{2}{*}{8.694} & \multirow[t]{2}{*}{0.878} \\
\hline & Low group & 120 & 11.06 & & \\
\hline \multirow[t]{2}{*}{ Extensor of $60 \%$} & High group & 222.83 & 24.63 & \multirow[t]{2}{*}{0.422} & \multirow[t]{2}{*}{0.229} \\
\hline & Low group & 215.32 & 23.17 & & \\
\hline \multirow[t]{2}{*}{ Flexor of $180 \%$} & High group & 86.08 & 10.92 & \multirow[t]{2}{*}{0.123} & \multirow[t]{2}{*}{0.122} \\
\hline & Low group & 90.44 & 10.02 & & \\
\hline \multirow[t]{2}{*}{ Extensor of $180 \%$} & High group & 147.25 & 12.74 & \multirow[t]{2}{*}{14.184} & \multirow[t]{2}{*}{0.118} \\
\hline & Low group & 140.86 & 17.98 & & \\
\hline \multirow[t]{2}{*}{ H/Q Ratio 60\% } & High group & 54.57 & 8.81 & \multirow[t]{2}{*}{2.073} & \multirow[t]{2}{*}{0.431} \\
\hline & Low group & 56.22 & 7.14 & & \\
\hline \multirow[t]{2}{*}{ H/Q Ratio 180\% } & High group & 58.57 & 6.7 & \multirow[t]{2}{*}{0.897} & \multirow[t]{2}{*}{0.001} \\
\hline & Low group & 64.66 & 6.58 & & \\
\hline
\end{tabular}

H/Q Ratio: hamstring/quadriceps ratio; SD: standard deviation. 
- Table 3 Correlation between pain perception (pain scale) and knee muscle strength and muscle endurance.

\begin{tabular}{|c|c|c|c|c|c|c|c|}
\hline & Pain scale & $\begin{array}{l}\text { Flexor of } \\
60 \%\end{array}$ & $\begin{array}{l}\text { Extensor of } \\
60 \%\end{array}$ & $\begin{array}{l}\text { Flexor of } \\
180 \%\end{array}$ & $\begin{array}{l}\text { Extensor of } \\
180 \%\end{array}$ & $\begin{array}{l}\mathrm{H} / \mathrm{Q} \text { ratio } \\
60 \%\end{array}$ & $\begin{array}{l}H / Q \text { ratio } \\
180 \%\end{array}$ \\
\hline Pain scale & 1 & - & - & - & - & - & - \\
\hline Flexor of $60 \%$ & -0.135 & 1 & - & - & - & - & - \\
\hline $\begin{array}{l}\text { Extensor of } \\
60 \%\end{array}$ & -0.112 & 0.298 & 1 & - & - & - & - \\
\hline Flexor of $180 \%$ & -0.34 & $0.817^{* *}$ & 0.21 & 1 & - & - & - \\
\hline $\begin{array}{l}\text { Extensor of } \\
180 \%\end{array}$ & 0.099 & $0.510^{* *}$ & $0.647^{* *}$ & $0.501^{* *}$ & 1 & - & - \\
\hline $\mathrm{H} / \mathrm{Q}$ ratio $60 \%$ & 0.012 & $0.611^{* *}$ & $-0.561^{* *}$ & $0.539^{* *}$ & -0.087 & 1 & - \\
\hline H/Q ratio $180 \%$ & $-0.436^{*}$ & 0.358 & $-0.402^{*}$ & $0.551^{* *}$ & $-0.441^{*}$ & $0.648^{* *}$ & 1 \\
\hline
\end{tabular}

- Table 4 Simple linear regression analysis between pain scale scores and hamstring/quadriceps (H/Q) ratio of $180 \%$.

\begin{tabular}{|c|c|c|c|c|c|}
\hline & B & Standard error & Beta & $\mathbf{T}$ & $p$-value \\
\hline Constant & 75.644 & 5.607 & - & 13.491 & 0.001 \\
\hline Pain scale & -3.072 & 1.198 & -0.436 & -2.564 & 0.016 \\
\hline
\end{tabular}

strength was similar irrespective of the living environment and position [14] could not be excluded. Sward et al. [16] demonstrated that different factors, such as muscle and motor functions, could influence the biomechanical and neuromuscular functions of the knee. In addition, Ardern et al. [17] found that players were resuming sports activities after regaining $90 \%$ of the knee flexor and extensor muscle strength of their uninjured knees because the criteria for determining their resumption of sports activities after surgery and rehabilitation were not standardized. Meanwhile, Angelozzi et al. [18] showed that knee injuries initially led to weakened muscle strength and muscle endurance. However, most injuries recover within 12 months. This probably explains why muscle strength and endurance of the knee flexor and extensor muscles were similar between the 2 groups in our study.

The 2 groups were similar in terms of muscle strength ratio of the flexor and extensor muscles of the knee. The perception of pain did not correlate with muscle strength of the flexor and extensor muscles of the knee. Although it is difficult to generalize, the average $\mathrm{H} / \mathrm{Q}$ ratio was $50-80 \%$ [19]. The proportion of the flexor and extensor muscles in the knee is $<60 \%$, which increases the risk of pain and sports injury [20]. This is because the flexor and extensor muscles of the knee act as the main and antagonistic muscles of each other and affect knee stability [19]. Accordingly, sports programs, such as the Nordic hamstring and FIFA 11 +, have been developed to strengthen the flexor muscles of the knee [20]. Howev$\mathrm{er}$, in this study, the muscle strength ratio of the knee flexor and extensor muscle (H/Q ratio) was similar between the 2 groups $(54.57 \pm 8.81$ and $56.22 \pm 7.14 \mathrm{NM}$ in the high and low groups, respectively). These results contradict those of a few previous studies. According to a few recent studies [21,22], the muscle strength ratio of the flexor and extensor muscles in the knee does not affect the risk of knee pain and sports injury. This difference is attributed to the biomechanical differences in structure between men and women [23].

Fujita et al. [21] and Kellis et al. [22] included only female participants in their studies. However, a few other studies $[19,20]$ recruited both genders. In general, women have genu recurvatum more frequently common than do men, and the quadriceps angles are also different between men and women [24]. In addition, injury to one knee can affect the other due to various factors [16]. Muscle strength and endurance can be recovered after most of the knee injuries [18].

In this study, a significant difference was observed between the 2 groups in terms of the muscle endurance ratio of the flexor and extensor muscles of the knees. In addition, the correlation analysis also showed that the pain scale correlated with the ratio of muscle endurance of the flexor and extensor muscles of the knee. The pain scale reading increased by 1 , and the muscle endurance ratio of the flexor and extensor muscles of the knee decreased by 3.07. Fousekis et al. [25] emphasized the strength of the knee flexor muscle because an imbalance of the knee flexor muscle could have a harmful effect. This implies that muscle endurance of the knee flexor 
muscle facilitates an increased functional ability to stabilize the knee. In addition, Bala et al. [12] reported that increased muscle endurance not only improves the metabolic capacity but also augments functions, movement, and oxidation capacity of the muscles. Therefore, apart from muscle endurance of the knee and muscle strength of the degenerating muscles, the H/Q ratio also signifies muscle strength and is related to pain perception. Aginsky et al. [26] reported that higher muscle strength of the extensor and muscle endurance of the flexor is proportional to the knee stability. Meanwhile, Haghighi et al. [27] reported that in addition to functional training, the Kinesio Taping could also help improve balance and functional performance. However, their study did not explicitly refer to competitive athletes. Therefore, further studies are needed to assess this issue.

It is pertinent to discuss some strengths and limitations to this study. In our study, many players were closely monitored for a year. The knee injuries that were sustained at the training facility were reported and processed within the site facility for consistent data collection. Concerning the limitation, our research considered the impact of the pain scale, disregarding severity of injuries and their mechanisms. Therefore, muscle changes due to severity of injury and mechanism were not elucidated. Long periods of rest without training could lead to atrophy. However, players who were seriously injured could not participate in competitions and training were excluded from the study to ensure data consistency. Therefore, further studies should be conducted to evaluate muscle strength regarding severity and mechanism of injury.

\section{Conclusions}

No significant differences in knee muscle strength, muscle endurance of both the flexor and extensor muscles, and muscle strength of the H/Q ratio were noted between the high and low groups. However, the ratio of muscle endurance of the flexor and extensor of the knee in the high group was significantly lower than that in the low group. Furthermore, the perception of pain correlated only with muscle endurance ( $\mathrm{H} / \mathrm{Q}$ ratio). The study results would be of significant benefit to handball players and basketball and soccer players. Furthermore, these results could help generate data necessary to develop rehabilitation programs for improving performance in these players in the future.

\section{Conflict of Interest}

The authors declare that they have no conflict of interest.

\section{References}

[1] International Handball Federation. 2020; Online https://www.ihf.info/ last accessed: 16.05.2020

[2] Korea Handball Federation. 2020; Online https://www.handballkorea. com/ last accessed: 16.05.2020

[3] Chung HK, Baek SS. Analysis of handball strategies of world top class team to prepare rio 2016 olympic games: focusing on women's team. Sport Sci 2017; 34: 175-180
[4] Mayer C. RühlemannA, J äger M. Handball injuries and their prevention. Orthopade 2019; 48: 1036-1041

[5] Kim HC, Park KJ. Correlation analysis of sports injuries and body composition and bone density in national water pool players. J Korean Soc Phys Med 2019; 14: 134-141

[6] Palmer-Green D, Fuller $C$, Jaques $R$ et al The injury/illness performance project (IIPP): A novel epidemiological approach for recording the consequences of sports injuries and illnesses. J Sports Med (Hindawi Publ Corp) 2013; 2013: 523974

[7] Steffen K, Engebretsen L. More data needed on injury risk among young elite athletes. Br J Sports Med 2010; 44: 485-489

[8] Kim CW, Park KJ. Injuries in female elite Korean handball athletes: A epidemiological study. J Korean Soc Phys Med 2020; 15: 93-100

[9] Kim HC, Park KJ. Injuries in male and female elite aquatic sports athletes: An 8-year prospective, epidemiological study. J Sports Sci Med 2020; 19: 390-396

[10] Park KJ, Kim CW. Injuries in Elite Korean kabaddi athletes: A epidemiological study. J Korean Soc Phys Med 2020; 15: 57-63

[11] Kang DH, Yu LY, Lee GC. The effects of knee extensor, flexor muscle strength and joint position sense in squat exercise on variety surface. J Korean Soc Int Med 2013; 1: 47-57

[12] Bala K, Gakhar M, Jagga V. Effect of endurance training of trunk extensor muscles on pain and endurance in patients with sub acute nonspecific low backache. J Exer Sci Physiother 2012; 8: 82-86

[13] Bahr R, Clarsen B, Derman W et al. International Olympic Committee consensus statement: methods for recording and reporting of epidemiological data on injury and illness in sport 2020 (including STROBE Extension for Sport Injury and Illness Surveillance (STROBESIIS)). Br J Sports Med 2020; 54: 372-389

[14] Kim HC, Park KJ. Analysis of correlation between the inspiratory capacity of the National softball players and the bone density, bone mass, muscle power, muscle endurance. J Korean Soc Phys Med 2020; 15: 95-104

[15] Øiestad BE, Juhl CB, Eitzen I et al. Knee extensor muscle weakness is a risk factor for development of knee osteoarthritis. A systematic review and meta-analysis. Osteoarthritis Cartilage 2015; 23: 171-177

[16] Sward P, Kostogiannis I, Roos H. Risk factors for a contralateral anterior cruciate ligament injury. Knee Surg Sports Traumatol Arthrosc 2010; 18: 277-291

[17] Ardern CL, Webster KE, Taylor NF et al. Return to sport following anterior cruciate ligament reconstruction surgery: A systematic review and meta-analysis of the state of play. Br J Sports Med 2011; 45: 596-606

[18] Angelozzi M, Madama M, Corsica C et al. Rate of force development as an adjunctive outcome measure for return-to-sport decisions after anterior cruciate ligament reconstruction. J Orthop Sports Phys Ther 2012; 42: 772-780

[19] Cheung RTH, Smith AW, Wong DPH. Q ratios and bilateral leg strength in college field and court sports players. J Hum Kinet 2012; 33: 63-71

[20] Islam MS, De A. Functional hamstring to quadriceps strength ratio $(\mathrm{H}: \mathrm{Q})$ and hamstrings injury of soccer players: A qualitative analysis. Orthop Sports Med 2018; 2: 126-132

[21] Fujita R, Matsui $Y$, Harada A et al. Does the $Q-H$ index show a stronger relationship than the $\mathrm{H}: \mathrm{Q}$ ratio in regard to knee pain during daily activities in patients with knee osteoarthritis? J Phys Ther Sci 2016; 28: 3320-3324

[22] Kellis E, Galanis N, Kofotolis N. Hamstring-to-quadriceps ratio in female athletes with a previous hamstring injury, anterior cruciate ligament reconstruction, and controls. Sports (Basel) 2019; 7: 214-223

[23] Harmon KG, Ireland ML. Gender differences in noncontact anterior cruciate ligament injuries. Clin Sports Med 2000; 19: 287-302 
[24] SmithH C, Vacek P, Johnson R], et al. Risk factors for anterior cruciate ligament injury a review of the literature - part 2: hormonal, genetic, cognitive function, previous injury, and extrinsic risk factors. Sports Health 2012; 4: 155-61

[25] Fousekis K, Tsepis E, Vagenas G.. Multivariate isokinetic strength asymmetries of the knee and ankle in professional soccer players. J Sports Med Phys Fitness 2010; 50: 465-474
[26] Aginsky JD, Neophytou N, Charalambous T. Isokinetic hamstring and quadriceps muscle strength profiles of elite South African football players. African J Phys Health Edu Recreation Dance 2015; 203: 1225-1236

[27] Haghighi FM, Mahbobeh S, Ebrahimian M et al. A comparison of the Effect of Quadriceps Taping versus Patellar Taping on Balance and Functional Performance in Patients with Knee Osteoarthritis. Phys Med Rehab Kuror 2019; 29: 275-281 